\title{
About Tatiana Vladykina
}

\author{
Anna Mutina \\ State Museum of the History of Religion, St Petersburg
}

How can we measure the success of a scholar or a folklorist? By the quantity of publications in the index databases? By the shelves full of books and fieldwork notebooks? By the amount of terabytes of photographs and recordings of conversations and songs? By the number of under- and postgraduate students who defended their dissertations under her supervision? By the recognition of their colleagues? By official awards, titles and certificates of merit?

Undoubtedly, all this is part of Tatiana Vladykina's biography, and it represents its external aspect, the visible and bright tapestry of her life. But when I think about Tatiana Vladykina, about the scholar, the teacher, and the person close to me, I want to talk about something else. She taught us, her doctoral students, attentively and thoughtfully, what is the painstaking work of the scholar, how to edit a text, how to work on records. And I believe that these meetings, which did not at all take place during tedious seminars and lectures, but were vibrant and heated conversations, shaped our relationship with our chosen profession. The life of young scholars at the turn of the $21^{\text {st }}$ century could not be described as unclouded. We often faced a dilemma: should we write another part of our dissertation, or look for our daily bread? But Tatiana 
Vladykina was able to help us not only with our articles but also in our search for work, for additional income. And as with research, her help always was kindly, unobtrusive, and sensitive. And how exciting was our fieldwork, our common trips to conferences. When looking at the photos, we remember everything: the compulsory morning porridge ritual, the night escapes to the disco (and the subsequent gossip), and of course the journeys made together, side by side. What is the unique quality of Tatiana Vladykina's personality? I would think, it is her rare gift to be able to see and to understand the Other. It is felt by her village partners, whom she asked about traditions and rituals; by her colleagues when they discuss scientific texts, by the heads and leaders of folklore groups coming to her for consultations, by folk masters and artists. And, last but not least, by her students. The range of the topics treated in the dissertations defended under Tatiana Vladykina's supervision is formidable: Udmurt and Russian singing tradition, ritual folklore, historical legends, the children's world, and much, much, more. And always she endeavoured to bring out the individual features of the students, to show their merit and never to dictate what was right, or what to write.

Attempting to get to the point, she delves deep into the structure of Udmurt rituals and folklore genres, uncovers the secret meaning in the words of a song, but also gives the same level of attention to her partner, endeavouring to listen, to help, to engage. And each of her investigations is about how we, birds on the tree of life, sing our own song, which harmoniously fits in with the general choir, as we are all caught in one stream of traditional culture, walking on different paths yet in the same direction. And I am happy that on this road Tatiana Vladykina has been, for long years, my companion. 


\section{Anna Mutina}

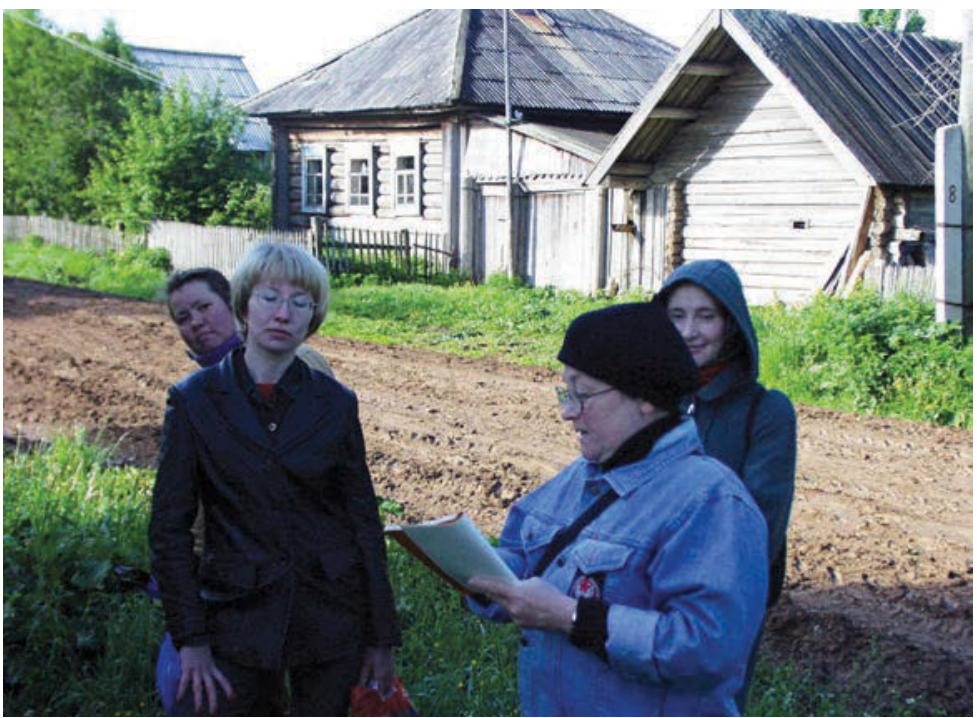

Photo 1. Fieldwork in the Kez district, Udmurtia. June 2004, Kuliga village. Tatiana Vladykina with her doctoral students: Tatiana Vladykina, Irina Pchelovodova, Elizaveta Lozhkina. Photograph: Anna Mutina

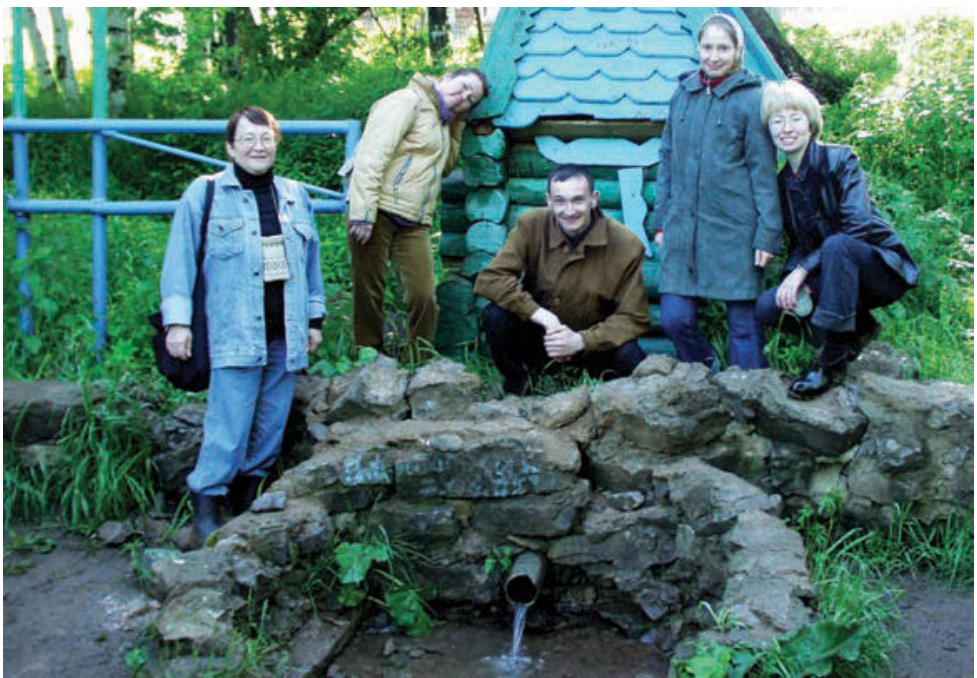

Photo 2. Fieldwork in the Kez district, Udmurtia. June 2004, Kuliga village. Tatiana Vladykina with her doctoral students at the source of the Kama (Tatiana Vladykina, Irina Pchelovodova, Elizaveta Lozhkina.). Photograph: Anna Mutina. 


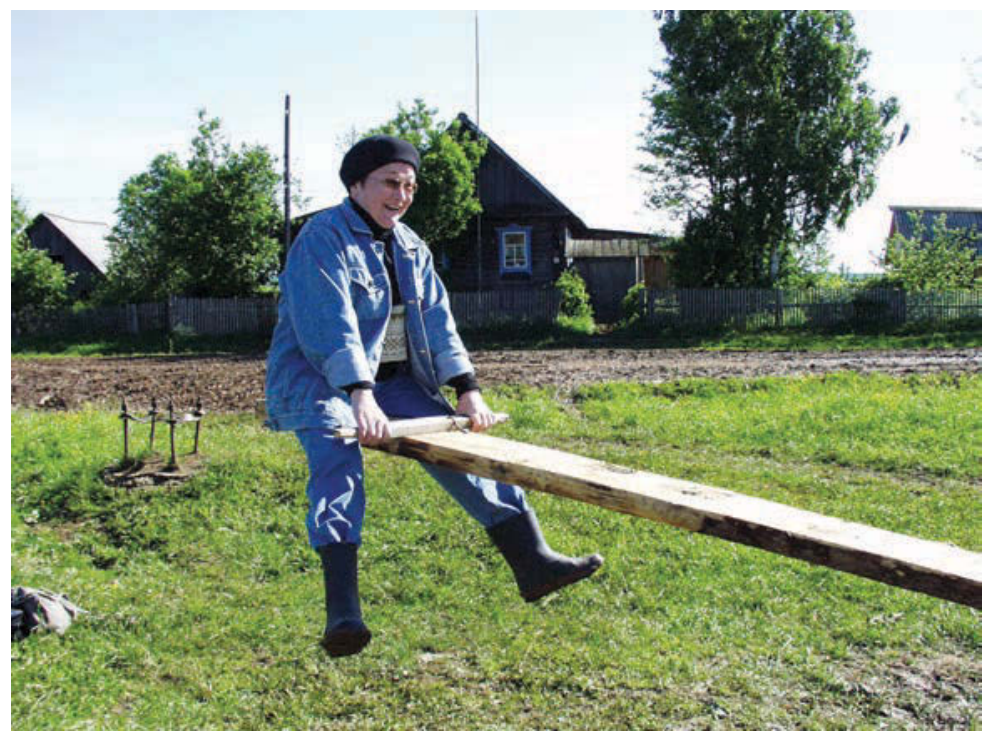

Photo 3. Fieldwork in the Kez district, Udmurtia. June 2004, Kuliga village. On the swing. Photograph: Anna Mutina.

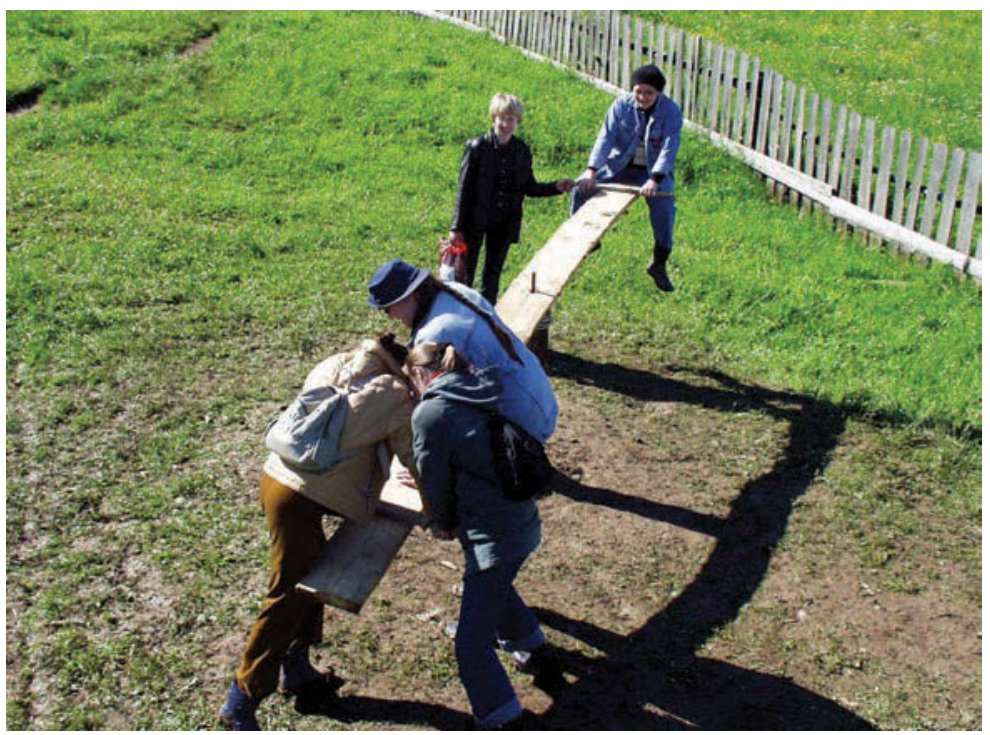

Photo 4. Fieldwork in the Kez district, Udmurtia. June 2004, Kuliga village. On the swing. Photograph: A. Nikulin. 


\section{Anna Mutina}

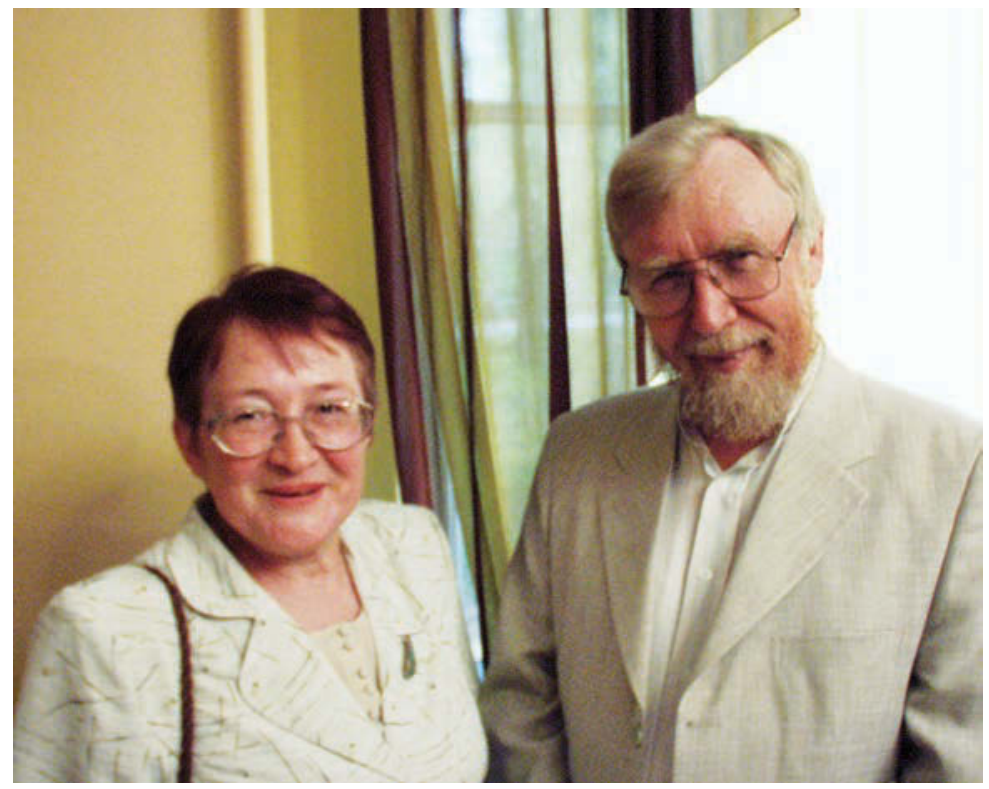

Photo 5. Beginning of the 2000. Photograph: Anna Mutina.

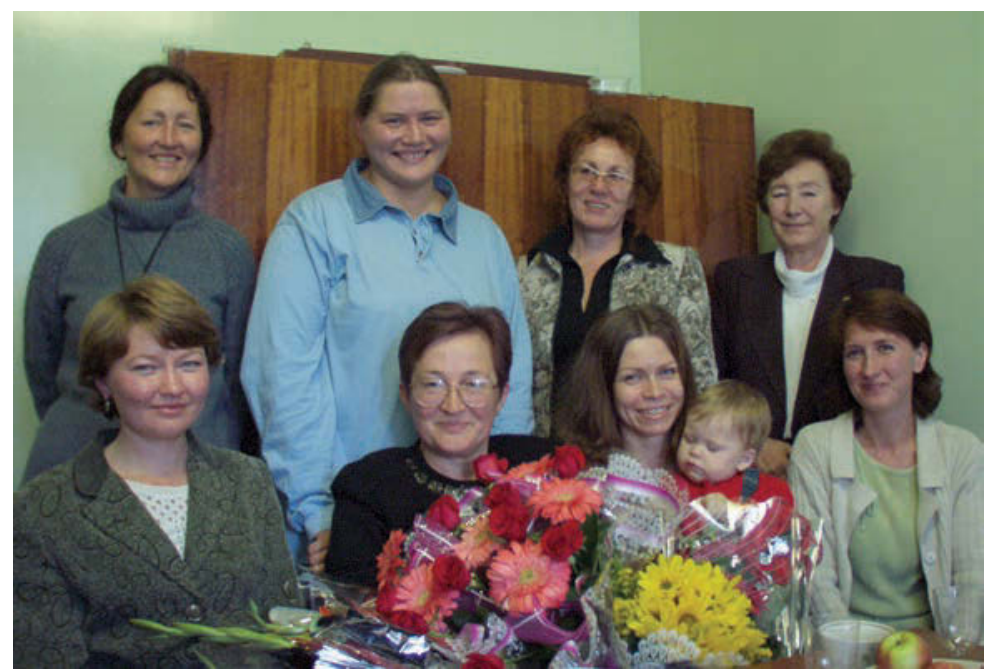

Photo 6. Beginning of the 2000. With colleagues. Below from left to right: Tatiana Zykina, Tatiana Vladykina, Yuliya Prikazchikova with her daughter, Alevtina Kamitova. Standing, from let to right: Irina Nuriyeva, Anna Mutina, Galina Nikitina, Margarita Ivanova. Photograph: Kuz'ma Kulikov. 
About Tatiana Vladykina

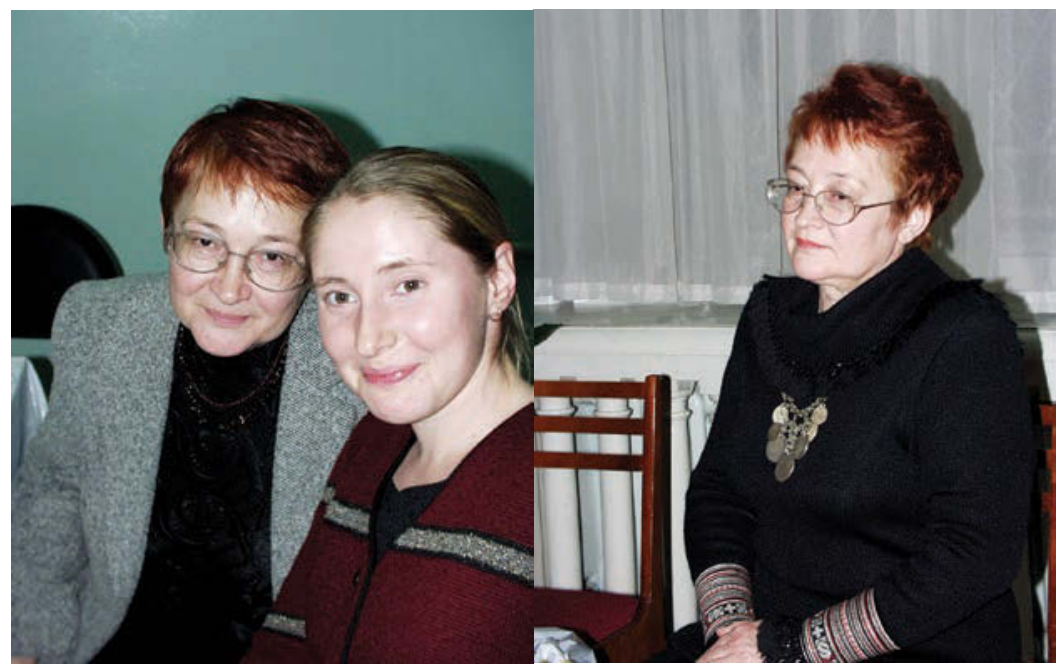

$7 \mathrm{a}$

$7 \mathrm{~b}$
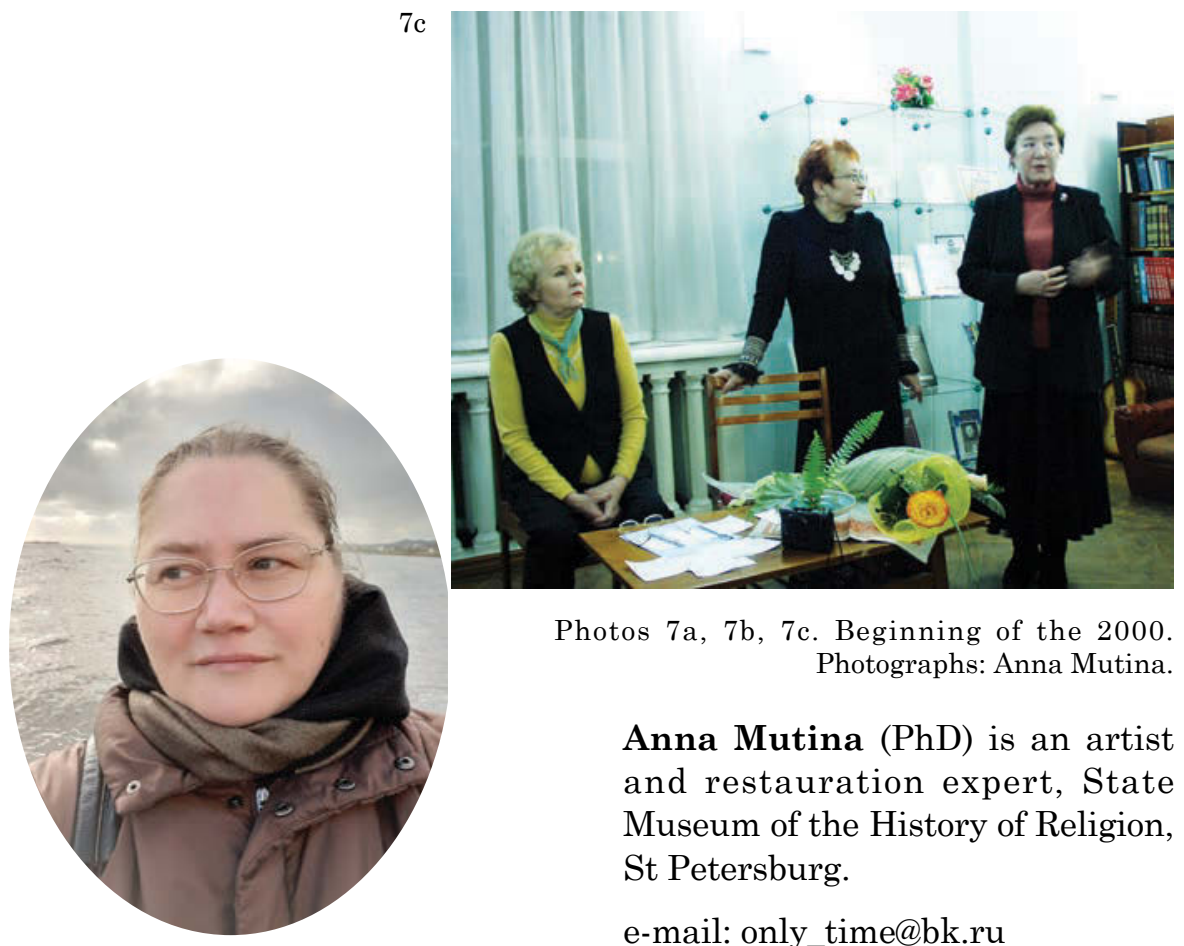

Photos 7a, 7b, 7c. Beginning of the 2000 . Photographs: Anna Mutina.

Anna Mutina $(\mathrm{PhD})$ is an artist and restauration expert, State Museum of the History of Religion, St Petersburg.

e-mail: only_time@bk.ru 